\title{
Electronic triage system for continuously monitoring casualties at disaster scenes
}

\author{
Keishi Sakanushi · Takuji Hieda - Taichiro Shiraishi • \\ Yasumasa Ode $\cdot$ Yoshinori Takeuchi $\cdot$ Masaharu Imai • \\ Teruo Higashino $\cdot$ Hiroshi Tanaka
}

Received: 16 December 2011/Accepted: 24 April 2012/Published online: 15 May 2012

(C) The Author(s) 2012. This article is published with open access at Springerlink.com

\begin{abstract}
Unfortunately, many persons are injured or killed during disasters. The problems of paper triage tags, which are widely used at disaster scenes, include an inability to show the current priorities of casualties and a failure to collect the physiological conditions of the casualties. To save lives, this paper proposes an electronic triage system that consists of two types of electronic triage tags and an electronic triage server. The electronic triage tag continuously monitors the vital signs of casualties and transmits them to the electronic triage server, and the electronic triage system shows the current priorities of the
\end{abstract}

K. Sakanushi $(\bowtie) \cdot$ T. Shiraishi · Y. Takeuchi · M. Imai ·

T. Higashino

Graduate School of Information Science and Technology,

Osaka University, 1-5 Yamadaoka, Suita, Osaka 565-0871,

Japan

e-mail: sakanusi@ist.osaka-u.ac.jp

Y. Takeuchi

e-mail: takeuchi@ist.osaka-u.ac.jp

M. Imai

e-mail: imai@ist.osaka-u.ac.jp

T. Higashino

e-mail: higashino@ist.osaka-u.ac.jp

T. Hieda

College of Science and Engineering, Ritsumeikan University,

1-1-1 Noji-Higashi, Kusatsu, Shiga 525-8577, Japan

e-mail: takuji.hieda@tomiyama-lab.org

Y. Ode $\cdot$ H. Tanaka

Department of Emergency and Critical Care Medicine,

Juntendo University Urayasu Hospital, 2-1-1 Tomioka,

Urayasu, Chiba 279-0021, Japan

e-mail: oode@juntendo-urayasu.jp

H. Tanaka

e-mail: htanaka@juntendo-urayasu.jp casualties. Experimental results show that our proposed electronic triage system can save more lives than paper triage tags.

\section{Introduction}

Unfortunately, disasters happen every year, and many persons are injured and killed in them. At disaster scenes, the number of casualties usually greatly exceeds the amount of medical resources. In such situations, providing sufficient medical care to all the casualties is difficult. Therefore, to save as many lives as possible, we must prioritize (triage) the casualties for treatment and transportation to hospitals by assessing their physiological conditions and vital signs.

To show the priorities of casualties, paper triage tags are currently used at disasters. A paper triage tag has four colored tags on its bottom and shows the priority by the color that is not torn off.

Even though paper triage tags have been widely used at disasters, they suffer from the following limitations:

- They cannot monitor vital signs.

- They do not show current priority based on the present physiological condition.

- Rescue commanders have difficulty collecting the overall physiological conditions of the casualties.

- Triage officers spend much time recording physiological conditions by pen because they are expected to triage one casualty within $60 \mathrm{~s}$.

This paper proposes and implements an electronic triage system for monitoring the casualties in disasters. Our proposed electronic triage system consists of two types of electronic triage tags and an electronic triage server. The 
electronic triage tags continuously measure vital signs, prioritize treatment and transportation to hospitals based on vital signs and physiological conditions, and electronically display the priority The electronic triage tags also wirelessly transmit the priority, the vital signs, and the physiological conditions to an electronic triage server located in the on-site rescue control center. The electronic triage server shows the real-time overall physiological conditions of the casualties and monitors the changes in their physiological conditions. We expect that our proposed electronic triage system will save many lives by quickly finding the casualties whose physiological conditions are worsening.

The rest of this paper is organized as follows. Section 2 introduces current disaster medical operations and related work. Section 3 proposes our new electronic triage system whose details are described in Sects. 4 and 5. Section 6 shows our experimental results and Section 7 provides a conclusion.

\section{Paper triage tags and related work}

\subsection{Triage at disaster scenes}

Unfortunately, many disasters happen every year, including accidents involving trains, airplanes, buses, and cars and others caused by explosions, fires, collapsing buildings, and terrorism. In such situations, tens or hundreds of persons are killed or injured, and many persons require immediate medical care. However, in the early stage of disaster response, the number of injured greatly exceeds the amount of such medical resources as doctors/nurses, rescue teams, ambulances, and medical supplies and equipment. In such situations, it is often impossible to adequately provide enough medical care to all the injured.

To prevent further loss of life, the order of treatment and transportation is crucial. To meet the above requirements, we must prioritize the treatment and the transportation of the injured by assessing their physiological conditions and vital signs by triage.

In disaster medicine, casualties are generally classified into four categories, each of which is usually represented by a color:

- Category I (Red): An injured person who will survive if he/she receives immediate treatment or transportation to a hospital. Persons in this category will not survive without immediate medical care.

- Category II (Yellow): An injured person whose treatment and transportation can be delayed and who can wait for treatment and transportation until the "Red" casualties have been addressed.

- Category III (Green): An injured person who only needs minor medical attention. Although the persons in this category are injured, they can walk and wait for

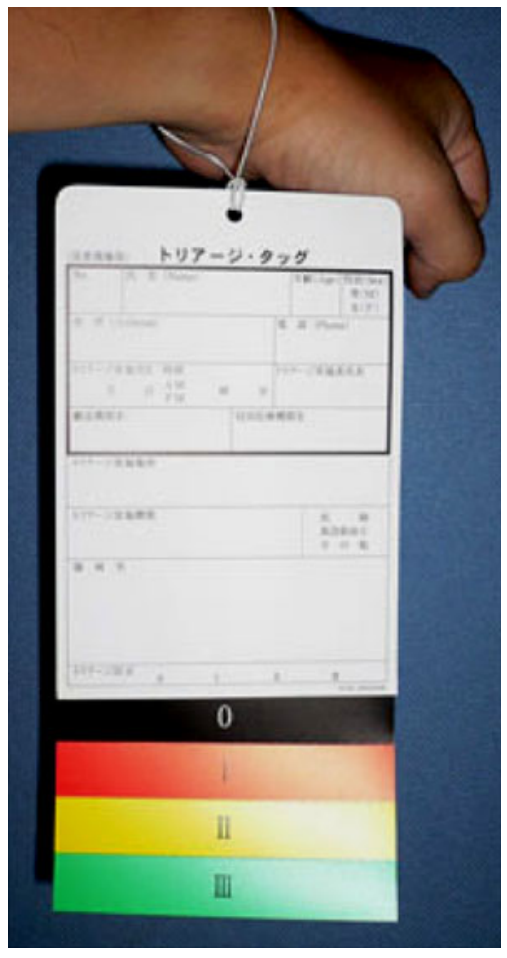

Fig. 1 Paper triage tag in Japan

treatment and transportation until the "Red" and "Yellow" casualties have been addressed.

- Category 0 (Black): A fatality, an injured person whose possibility of survival is very low, or an injured person who requires many medical resources to survive.

Note that these categories represent the priority of treatment and transportation to hospitals. Since the physiological conditions of casualties may change suddenly, continuously updated periodical examinations are required.

\subsection{Paper triage tags}

The paper triage tag shown in Fig. 1 is currently used at disaster scenes. It has a form on which to record personal information of the casualty and at the bottom cutoff tags: black, red, yellow, and green.

The triage officer examines all the casualties at the disaster scene to decide their priority. Based on the priority, the triage officer cuts the unnecessary color tags from the paper triage tag and attaches it to the casualty. Casualties are treated and transported to hospitals based on the priority order. The triage officer also writes down the physiological condition of the casualty.

\subsection{Simple triage and rapid treatment (START)}

In incidents with mass casualties, time is precious. All casualties must be classified as quickly as possible so that treatment and transportation can be started. 
The most important factors for survival are circulation and respiration. Since disorders of the circulatory and respiratory systems directly cause death, we must immediately identify casualties whose circulatory or respiratory system conditions are severely damaged.

Simple triage and rapid treatment (START) is one method for finding such casualties (Benson et al. 1996).

The START method is widely used since it classifies casualties into four categories without medical equipment. Triage officers are generally expected to prioritize casualties within $60 \mathrm{~s}$. The following is the flow of the START method (Fig. 2):

(1) Assessment of walking: If the casualty can walk, he/ she is placed in Category III, Green. If he/she cannot walk, go to assessment (2).

(2) Assessment of respiration: If he/she can respire spontaneously, go to (3). If he/she cannot, the triage officer immediately opens the airway. If respiration recovers, he/she is placed in Category I, Red. If he/ she cannot respire spontaneously after opening the airway, he/she is placed in Category 0, Black.

(3) Assessment of breath rate: The triage officer examines the casualty's breath rate. If her breath rate is not normal $(10[\mathrm{rpm}] \leq$ breath rate $\leq 30[\mathrm{rpm}])$, he/she is placed in Category I, Red. Otherwise, go to assessment (4).

(4) Assessment of capillary refill time (CRT): If her CRT is not normal $(\mathrm{CRT} \leq 2[\mathrm{~s}])$, he/she is placed in Category I, Red. Otherwise, go to assessment (5).

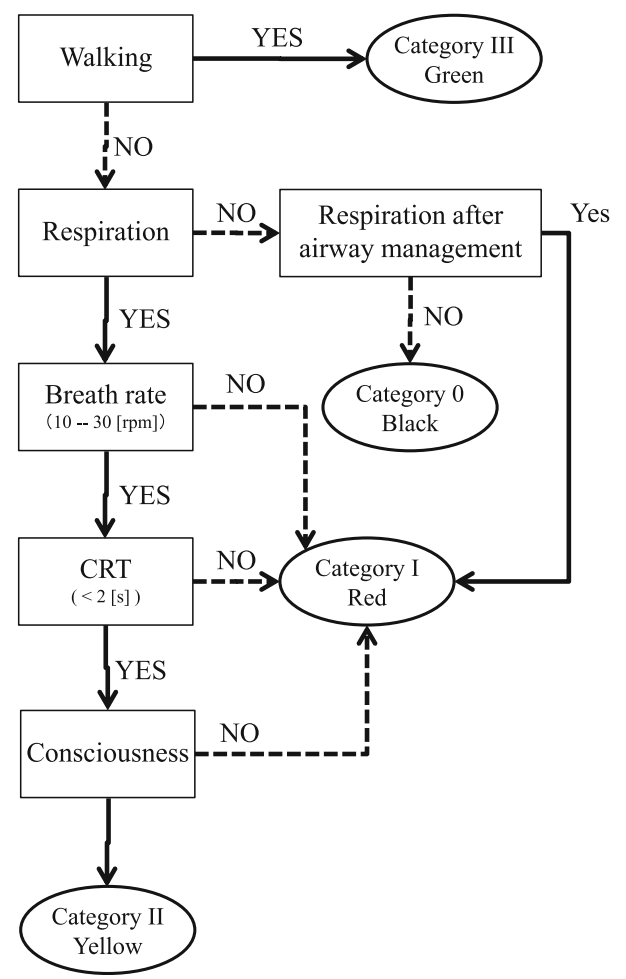

Fig. 2 START method
(5) Assessment of consciousness: If he/she can follow simple commands, he/she is placed in Category II, Yellow. If he/she cannot, he/she is placed in Category I, Red.

Note that since CRT, which is the amount of time required for empty capillaries to refill, is used as a circulation index in the START method, it can be easily evaluated without medical equipment by lightly pressing a casualty's fingernail. The color of the pressed fingernail will turn white and return to pink after the pressure is removed. CRT is the time required by the color to change from white to pink.

\subsection{Disaster rescue operation by paper triage tags}

Figure 3 shows the current disaster rescue operation flow using paper triage tags.

1. Rescue: Casualties are rescued from disaster areas and transported to the triage post.

2. Triage: At the triage post, they are classified into four categories by examining their physiological conditions based on the START method. Based on the casualty's priority, the unnecessary color tags are removed from the paper triage tag, which is attached to the casualty.

3. Treatment: They are transported to the zone corresponding to the priority color in the treatment area or the temporary morgue and treated in the priority order.

4. Transportation: They are transported to hospitals in the priority order.

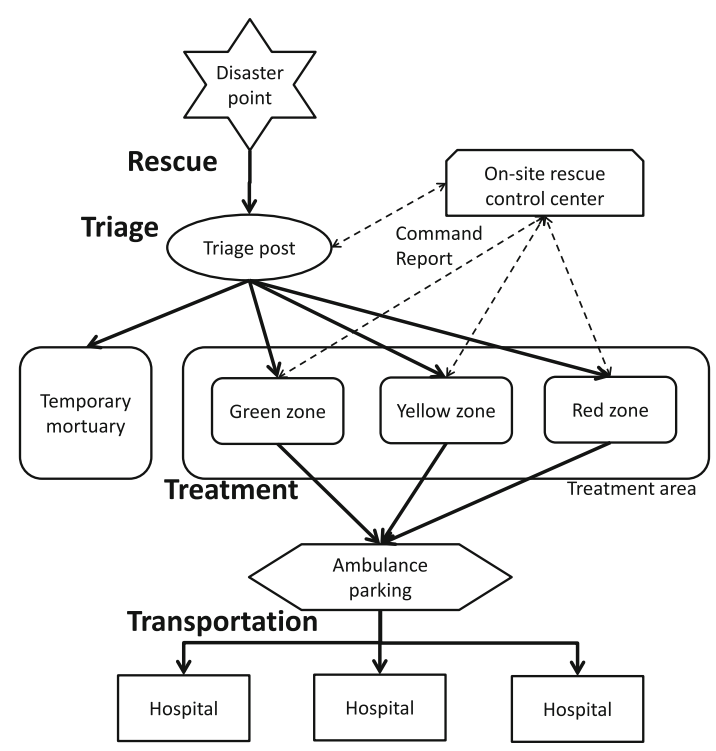

Fig. 3 Disaster rescue operation flow 


\subsection{Problems with paper triage tags}

Even though paper triage tags are widely used at disaster scenes, they have the following obvious limitations:

Lack of real-time monitoring: They cannot measure the vital signs or continuously monitor a casualty's physiological conditions.

No current priority: They do not show the current priority based on the casualty's present physiological condition because they cannot monitor vital signs. In other words, paper triage tags only show the past priority that reflects when a casualty was first examined and triaged. Since the casualty's priority is not changed, even if their physiological condition becomes critical, a casualty might die due to treatment and transportation delays.

Difficulty of collecting physiological conditions: During an incident with mass casualties, many are transported from the disaster area to the triage post and from the triage post to hospitals. To dynamically decide the treatment and transportation order, updated information is strongly required. However, the rescue commander collects the information of casualties by transceivers or oral reports. Therefore, rescue commanders have difficulty collecting the overall physiological conditions of casualties at disaster scenes in real time.

Time required to attach tags: Triage officers are expected to triage one casualty within $60 \mathrm{~s}$. However, since they must write the physiological conditions by pen and paper, finishing within such a short time is very difficult.

\subsection{Related work}

In this section, we introduce related work on triage tags and wireless monitoring systems on telemedicine systems.

A triage system that consists of a paper triage tag with an embedded RF-ID chip, a portable smart device with an RF-ID reader, and a triage server in (Sonoda et al. 2007). First, the triage officer decides the category and attaches a paper triage tag to the casualty. Then the triage officer inputs the category to the portable smart device and reads the tag ID by the RF-ID reader. The portable smart device wirelessly transmits the tag ID and the category to the triage server. In this system, even though the triage server collects information of the casualties, it cannot update the priorities in real time.

A wireless network to disaster scenes (Banitsas et al. 2001; Midkiff and Bostian 2002), and a wireless triage system (Wendelken et al. 2004; Ryan et al. 2011a, b) are introduced. However, they only briefly sketched the structures and components of their systems without discussing or implementing them.

Many wireless monitoring systems on telemedicine have been proposed, including a wireless network that connects wards and remote hospitals by laptop computers (Banitsas et al. 2001), a PDA-based teleradiology system
(Georgiadis et al. 2004), a PDA-based system for monitoring electromagnetic signals (Georgiadis et al. 2006), a telemonitoring system on electromagnatic signals by smartphones and 3G wireless networks (Cavouras et al. 2008), and a PDA-based teleradiology terminal (Ninos et al. 2010). The systems proposed in (Kim and Le 2008) can wirelessly monitor pulse rate, $\mathrm{SpO}_{2}$, and electrocardiogram. A context-aware service discovery for healthcare using wireless body sensor network is proposed by Fenza et al. (2012). However, their target situations are not disaster scenes.

The systems proposed in (Pavlopoulos et al. 1998; Lorincz et al. 2004; Malan et al. 2004; Shnayder et al. 2005) can monitor the pulse rate and $\mathrm{SpO}_{2}$ of casualties and transmit them to the server. The systems proposed by Ahn et al. (2008) can monitor the pulse rate and electrocardiogram of casualties and transmit them to the server. The rescue commander can monitor casualties in real time. However, they do not prioritize casualties.

The systems proposed by Gao et al. (2007, 2008) not only can monitor the vital signs of casualties but can also input a priority category for them. However, since a casualty's physiological conditions cannot be input to the system, the rescue commander cannot collect breath rates and physiological conditions. Since these systems cannot measure breath rates, they cannot monitor the respiratory systems of casualties, and it is difficult to appropriately manage treatment and transportation order in real time.

The systems proposed by Gao et al. (2007, 2008), Ahn et al. (2008), Maltz et al. 2006, Yu and Ganz (2011) can tracking casualties using GPS or wireless networks at the disaster scene. However, they do not prioritize casualties.

\section{Electronic triage system}

To solve the problems described in Sect. 2.5, this paper proposes a new electronic triage system. Figure 4 shows a

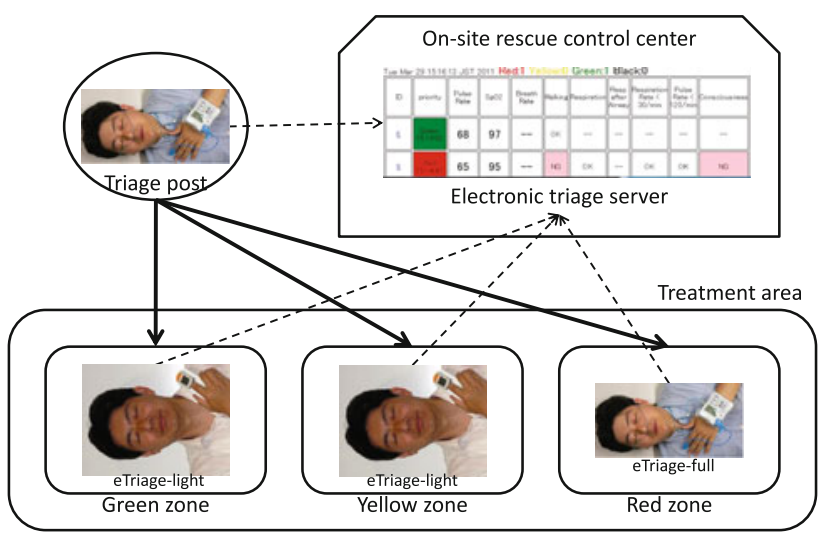

Fig. 4 Sketch of proposed electronic triage system 


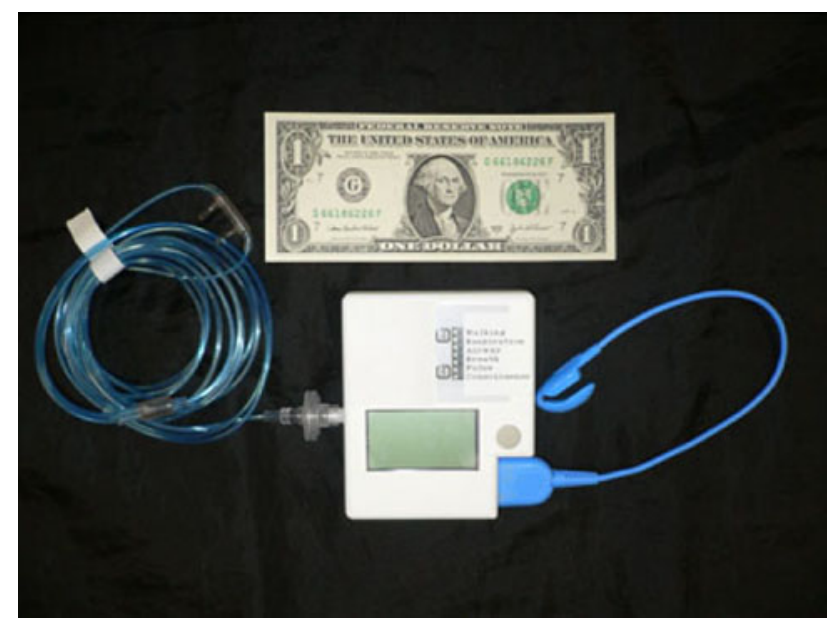

Fig. 5 eTriage-full

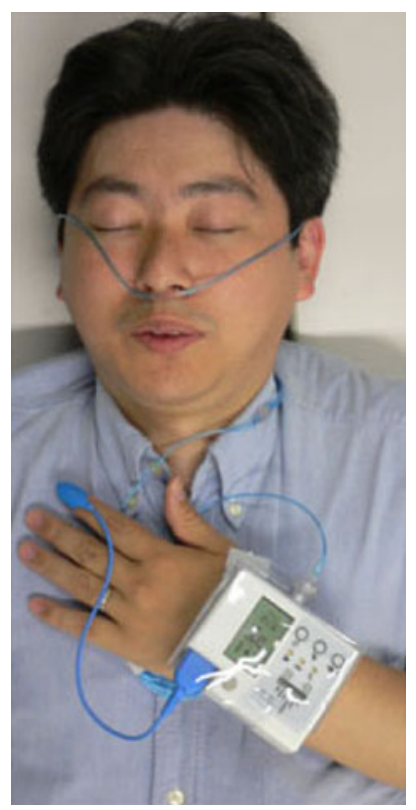

Fig. 6 Attachment of eTriage-full

sketch of our proposed electronic triage system that consists of two types of electronic triage tags, eTriage-full and eTriage-light, which are attached to the casualties and the triage server located in the on-site rescue control center.

eTriage-full: eTriage-full (Fig. 5) can measure the pulse rate, $\mathrm{SpO}_{2},{ }^{1}$ and the breath rate. eTriage-full has a finger probe and a canula, which are attached to a finger and the casualty's nose, respectively (Fig. 6). The pulse rate and $\mathrm{SpO}_{2}$ are measured by the finger probe, and the breath rate is measured by the canula.

\footnotetext{
${ }^{1}$ Percutaneous oxygen saturation: saturation rate of oxygen in blood.
}

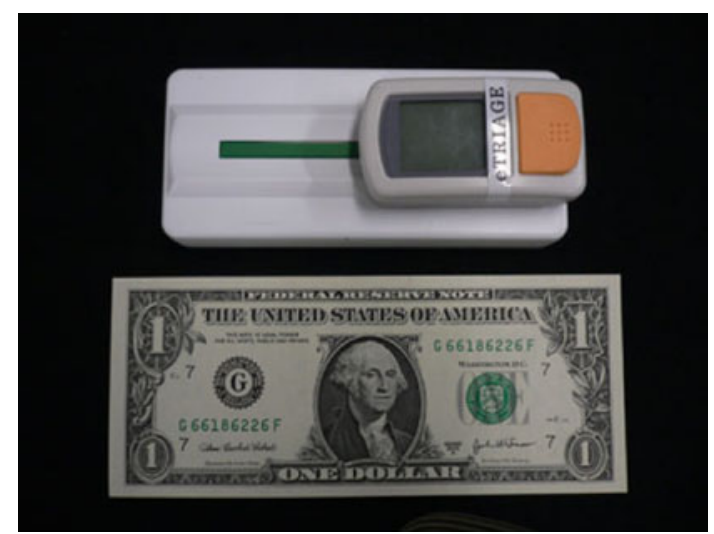

Fig. 7 eTriage-light

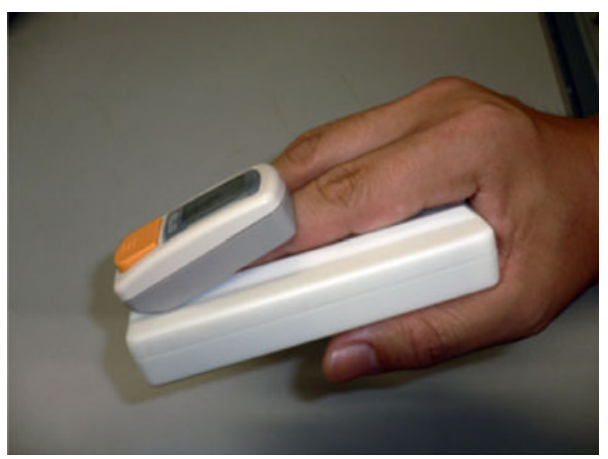

Fig. 8 Attachment of eTriage-light

eTriage-light: eTriage-light (Fig. 7) can measure the pulse rate and $\mathrm{SpO}_{2}$. Since eTriage-light has a built-in sensor, it can be attached quickly by inserting a finger (Fig. 8).

eTriage-full and eTriage-light are attached to casualties based on their physiological conditions. Since eTriage-full has a finger probe and a canula, attaching it quickly to a casualty is difficult. Therefore, eTriage-light is attached to most casualties since the time for attachment is shorter under time pressure. eTriage-full is attached to a casualty whose physiological condition is severe, i.e., those classified into Category I, Red, since it can observe the respiration conditions in detail.

eTriage-full and eTriage-light continuously measure vital signs and automatically decide the priority category based on the measured vital signs and the physiological conditions of the casualties. eTriage-full and eTriage-light can wirelessly transmit information to the triage server at the on-site rescue control center.

Our electronic triage system shows the overall physiological conditions of casualties and the information received from electronic triage tags and monitors the 
Table 1 Specifications of electronic triage tags

\begin{tabular}{|c|c|c|}
\hline & eTriage-full & eTriage-light \\
\hline Sensor & $\begin{array}{l}\text { Pulse rate, } \mathrm{SpO}_{2} \text {, breath } \\
\text { rate }\end{array}$ & Pulse rate, $\mathrm{SpO}_{2}$ \\
\hline $\mathrm{CPU}$ & ARM $920 \mathrm{~T} 180 \mathrm{MHz}$ & ARM $920 \mathrm{~T} 180 \mathrm{MHz}$ \\
\hline Memory & $\begin{array}{l}512 \text { KB RAM, } 4 \text { MB } \\
\text { Flash }\end{array}$ & $\begin{array}{l}512 \text { KB RAM, } 4 \text { MB } \\
\text { Flash }\end{array}$ \\
\hline Wireless IF & IEEE $802.15 .42 .4 \mathrm{GHz}$ & IEEE $802.15 .42 .4 \mathrm{GHz}$ \\
\hline Input IF & Pushbutton switch $\times 2$ & Pushbutton switch $\times 2$ \\
\hline $\begin{array}{l}\text { Output IF } \\
\text { (LED) }\end{array}$ & RGB LED x 8 & RGB LED x 8 \\
\hline $\begin{array}{l}\text { Output IF } \\
\text { (LCD) }\end{array}$ & LCD x 1 & LCD $\times 1$ \\
\hline Size & $\begin{array}{c}10 \mathrm{~cm}(\mathrm{~W}) \times 8.3 \mathrm{~cm} \\
(\mathrm{~L}) \times 2.9 \mathrm{~cm}(\mathrm{D})\end{array}$ & $\begin{array}{l}5 \mathrm{~cm}(\mathrm{~W}) \times 11.7 \mathrm{~cm} \\
(\mathrm{~L}) \times 3.9 \mathrm{~cm}(\mathrm{D})\end{array}$ \\
\hline Weight & $156 \mathrm{~g}$ & $123 \mathrm{~g}$ \\
\hline Battery & 720 mAh Li-ion & 720 mAh Li-ion \\
\hline Operation time & $7.5 \mathrm{~h}$ & $10 \mathrm{~h}$ \\
\hline
\end{tabular}

changes in their physiological conditions. eTriage-full and eTriage-light are used for different types of casualties. However, since the wireless communication and the interface of eTriage-full and eTriage-light share specifications for usability, they can be used together in our proposed system.

\section{Electronic triage tags: eTriage-full and eTriage-light}

This section introduces the details of our two types of electronic triage tags: eTriage-full and eTriage-light. Table 1 shows their specifications.

\subsection{Modules of electronic triage tags}

Figure 9 shows the block diagram of eTriage-full and eTriage-light. Both electronic triage tags consist of vital sensor, Interface, RF, and control units.

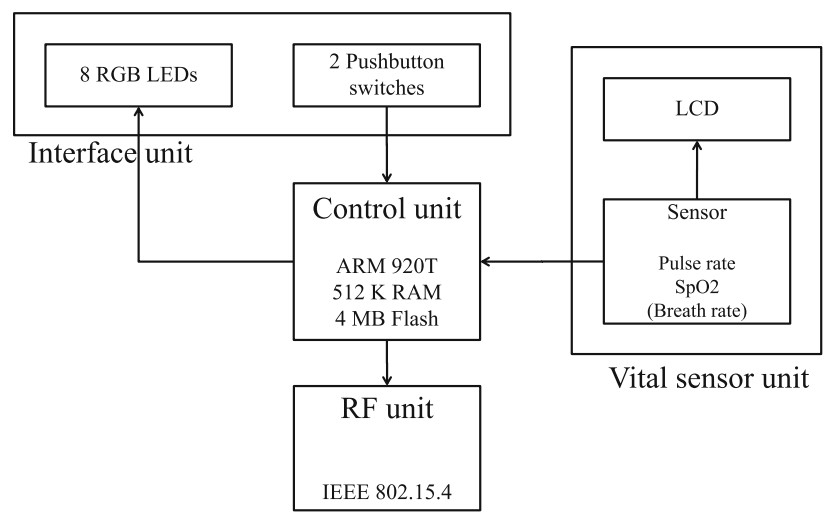

Fig. 9 Block diagram of eTriage-full and eTriage-light

\subsubsection{Sensor unit}

The sensor unit of eTriage-full has a finger probe, a canula, and an LCD panel (Fig. 10). eTriage-full measures the pulse rate and $\mathrm{SpO}_{2}$ by the finger probe and the breath rate by the canula. The measured values are continuously displayed on the LCD panel (Fig. 10).

eTriage-light, which has a built-in photonic sensor and an LED (Fig. 11), is attached to a finger, and its built-in photonic sensor measures the pulse rate and $\mathrm{SpO}_{2}$.

The measured values are continuously displayed on the LCD panel (Fig. 12).

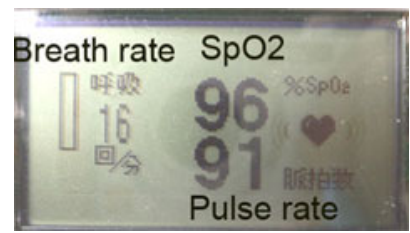

Fig. 10 LCD panel of eTriage-full

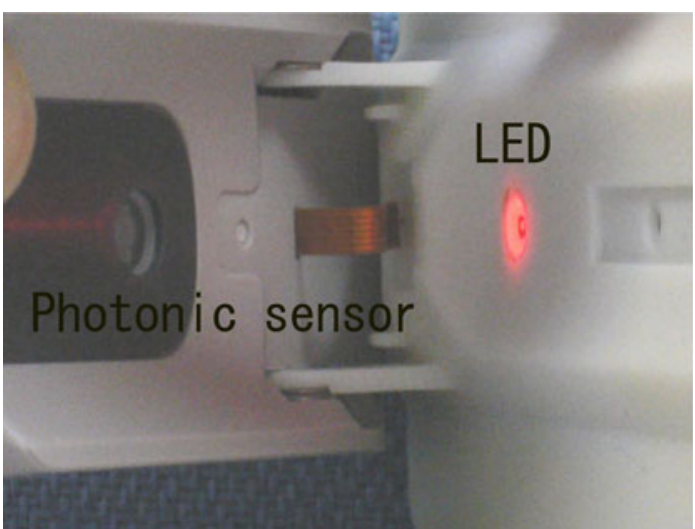

Fig. 11 eTriage-light's built-in photonic sensor and LED

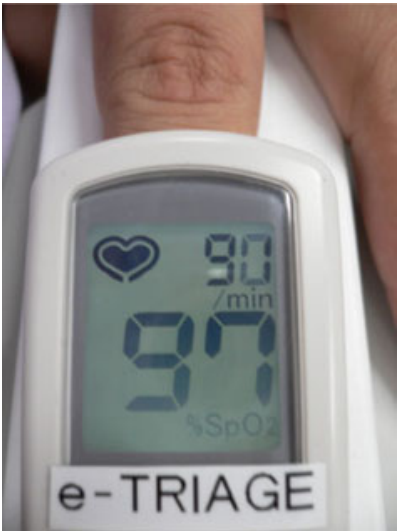

Fig. 12 eTriage-light's LCD panel 


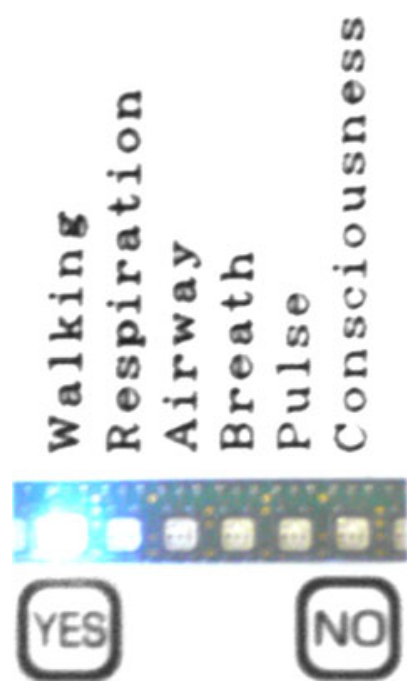

Fig. 13 Interface of electronic triage tag

\subsubsection{Interface unit}

The interface units of eTriage-full and eTriage-light have identical specifications and consist of eight RGB LEDs and two pushbutton switches (Fig. 13). LEDs display the color of a casualty's category.

The triage officers use pushbutton switches to input the physiological conditions of a casualty. Questions about the physiological conditions that are used to determine the priority are printed above the LEDs (Fig. 13). They input the physiological conditions to answer the questions by YES/NO pushbutton switches.

Six LEDs correspond to six questions. White denotes the waiting input for the corresponding question. Green means a YES answer to the corresponding question. Red means NO answer.

\subsubsection{RF unit}

The RF units of eTriage-full and eTriage-light have identical specifications. The electronic triage tag has a IEEE 802.15.4 2.4 GHz wireless interface and constructs an ad hoc wireless network. The electronic triage tag transmits vital signs, the priority, and the physiological conditions of a casualty to the electronic triage server over the ad hoc wireless network.

\subsubsection{Control unit}

The control units of eTriage-full and eTriage-light also have identical specifications. The control unit consists of a $180 \mathrm{MHz} 32$ bit ARM processor, $512 \mathrm{~KB}$ RAM, and $4 \mathrm{MB}$ flash memory. The control units manage other units.

\subsection{Features}

This subsection introduces several features of eTriage-full and eTriage-light.

\subsubsection{Detailed triage mode}

The electronic triage tag provides a detailed triage mode to triage officers. In the detailed triage mode, the triage officer inputs a casualty's physiological conditions by the interface of the electronic triage tag (Sect. 4.1.2) that decides the casualty's priority based on the inputted physiological conditions: the pulse rate, $\mathrm{SpO}_{2}$, walking ability, and consciousness.

The electronic triage tag decides the priority based on the START method. The difference from the START method is only the CRT assessment. The START method uses CRT, which is one simple index that can be measured without medical equipment, as an index of circulation. However, we use pulse rate instead of CRT to assess the circulatory system because it is another index of the circulatory system and can be measured by electronic triage tags. We define the normal pulse rate range as 50 $[\mathrm{rpm}] \leq$ pulse rate $\leq 120[\mathrm{rpm}]$.

Figure 14 shows the flow for determining the priority by electronic triage tags and LED lighting at each assessment. The flow details are described as follows:

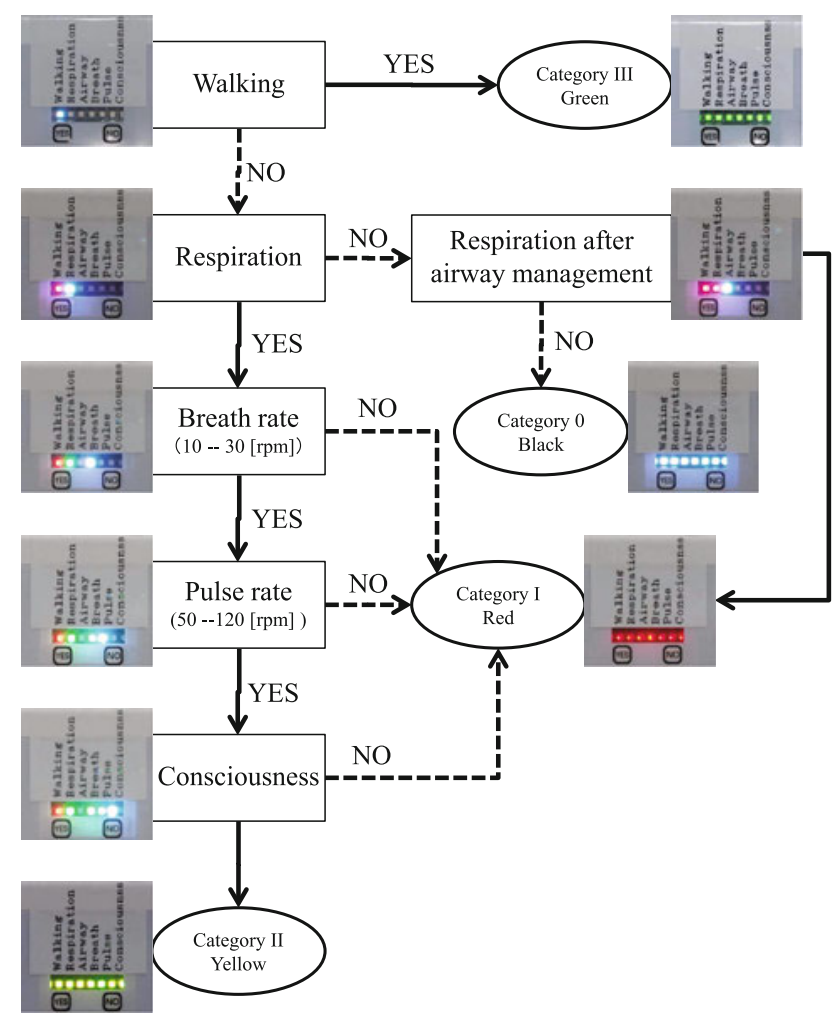

Fig. 14 Triage flow by electronic triage tag 
(1) Assessment of walking: At this phase the "Walking" LED is white, and the electronic triage tag is waiting for input of the physiological condition of the casualty and asks, "Can he/she walk?" If he/she can walk, the triage officer pushes YES button, and the electronic triage tag chooses priority Category III, Green and turns on all of the green LEDs. If the casualty cannot walk, the triage officer pushes NO button, and the electronic triage tag turns on the red LED and goes to assessment (2).

(2) Assessment of respiration: At this phase, the "Respiration" LED is white. The triage officer assesses the casualty's spontaneous respiration. If the casualty can respire spontaneously, the triage officer pushes YES button, and the LEDs become green, and the triage officer goes to assessment (3). If he/she cannot respire spontaneously, the triage officer pushes NO button, and the LEDs become red and the "Airway" LED becomes white. The triage officer immediately opens the airway. If the casualty's respiration recovers, the triage officer pushes YES button, and the casualty is placed in Category I, Red, and all the LEDs become red. If the casualty's respiration does not recover, the triage officer pushes NO button, and the casualty is placed in Category 0 , Black, and all the LEDs become white. Note that we use white to represent Category 0, Black, instead of turning off the LEDs to distinguish Category 0 from tag malfunctions.

(3) Assessment of breath rate: When the "Breath" LED is white, the system wants input about the casualty's breath rate. If it is not normal $(10[\mathrm{rpm}] \leq$ breath rate $\leq 30[\mathrm{rpm}])$, the triage officer pushes NO button, and the casualty is placed in Category I, Red, and all the LEDs become red. Otherwise, the triage officer pushes YES button, and the LEDs become green, and the triage officer goes to assessment (4).

(4) Assessment of pulse rate: When the "Pulse" LED is white, the system wants input about the casualty's pulse rate. If it is not normal $(50[\mathrm{rpm}] \leq$ pulse rate $\leq 120[\mathrm{rpm}])$, the triage officer pushes $\mathrm{NO}$ button. The casualty is placed in Category I, Red, and all the LEDs become red. Otherwise, the triage officer pushes YES button, and the LEDs become green, and the system goes to assessment (5).

(5) Assessment of consciousness When the "Consciousness" LED is white, the system wants input about whether the casualty can follow simple commands. If yes, the triage officer pushes YES button, and the casualty is placed in Category II, Yellow, and all the LEDs become yellow. Otherwise, push NO button, and the casualty is placed in Category I, Red, and all the LEDs become red.

\subsubsection{Simple triage mode}

In this paper we assume that a triage officer triages casualties with our proposed electronic triage tag. The detailed triage mode is not sufficient to triage casualties quickly if mass casualties occurred or the triage officer has not arrived early enough. The electronic triage tag can provide a simple triage mode to support triage under such situations. In the simple triage mode, the electronic triage tag automatically decides a casualty's priority based on the measured vital signs without input by triage officers.

The circulatory and respiratory systems are the most important factors for human life. Circulatory disorder causes cardiac standstill, which means death, and acute respiration disorder will eventually cause circulatory disorder. The pulse rate and $\mathrm{SpO}_{2}$ are the indexes to assess the circulatory system, and the breath rate assesses the respiration system. Note that since respiration disorder decreases oxygen in the blood, $\mathrm{SpO}_{2}$ will fall. Therefore we can use it to assess the circulatory system.

eTriage-light can triage casualties based on the measured vital signs. eTriage-light decides the priority category through the pulse rate and $\mathrm{SpO}_{2}$ as follows.

- Category I (Red): satisfies one of the following

- Pulse rate $<50[\mathrm{rpm}]$ or $>120[\mathrm{rpm}]$

- $\mathrm{SpO}_{2}<90 \%$

- Category II (Yellow): satisfies one of the following

- $50[\mathrm{rpm}] \leq$ pulse rate $<60[\mathrm{rpm}]$ or $100[\mathrm{rpm}]$ $<$ pulse rate $\leq 120[\mathrm{rpm}]$

- $90 \% \leq \mathrm{SpO}_{2}<96 \%$

- Category III (Green): satisfies the following

- $60[\mathrm{rpm}] \leq$ pulse rate $\leq 100[\mathrm{rpm}]$

- $96 \% \leq \mathrm{SpO}_{2} \leq 100 \%$

eTriage-full can measure breath rate as an index of the circulatory system. However, the time required to attach eTriage-full is long. In this paper, we implement this feature on eTriage-light since it can be attached in a few seconds (Table 2).

Table 2 Relations between vital signs and priority level

\begin{tabular}{lll}
\hline & eTriage-full & eTriage-light \\
\hline Pulse rate $[\mathrm{rpm}]$ & Category I red & $<50$ or $>120$ \\
& Category II yellow & $50-60$ or $100-120$ \\
& Category III green & $60-100$ \\
$\mathrm{SpO}_{2}[\%]$ & Category I red & $<90$ \\
& Category II yellow & $90-96$ \\
& Category III green & $96-100$ \\
\hline
\end{tabular}




\subsubsection{Monitoring vital signs}

The electronic triage tag continuously measures the vital signs (pulse rate, $\mathrm{SpO}_{2}$, and breath rate) and flashes the LEDs in their priority colors at the intervals of the measured the pulse rate. Moreover, it wirelessly transmits the vital signs to the electronic triage server once a minute.

\subsubsection{Notification}

The electronic triage tag changes into the notification mode in the following cases:

- when it finds abnormal data on the measured vital signs.

- when the rescue commander finds a casualty whose physiological condition has drastically changed by the electronic triage server.

- when one hour has passed from the previous triage or examination.

In the notification mode, LEDs on the electronic triage tag become blue, and the electronic triage tag sounds a buzzer to notify the rescue teams around the casualty. A rescue team rushes to the casualty, re-assesses it, does a detailed triage with the electronic triage tag, and enters its physiological condition into the electronic triage tag.

\section{Electronic triage server and rescue operation}

\subsection{Electronic triage server}

The electronic triage server is located at the on-site rescue control center to monitor the overall physiological conditions of the casualties at disaster scenes. Figure 15 shows a display with the following information on it:

- Number of casualties in Red, Yellow, Green, or Black category

\begin{tabular}{|c|c|c|c|c|c|c|c|c|c|c|}
\hline DD & serionity & Pulse Rase & $\mathrm{SeO2}$ & Breveh Rote & Wabine & Pensiration & $\begin{array}{l}\text { Rese } \\
\text { Ather } \\
\text { Arraty }\end{array}$ & $\begin{array}{l}\text { Breat: } \\
\text { Rath }\end{array}$ & $\begin{array}{l}\text { Puse } \\
\text { Rate: }\end{array}$ & Consciovanes: \\
\hline 1 & $\begin{array}{l}\text { Yelow } \\
\text { os } 2220\end{array}$ & 80 & 97 & - & No & OK & - & oK & ok & OK \\
\hline 2 & $\cos _{0012}$ & 75 & 98 & - & oK & - & - & - & - & - \\
\hline 15 & $\begin{array}{l}\text { Yollon } \\
183636\end{array}$ & 84 & 96 & - & NG & oK & - & oK & ok & o\% \\
\hline 16 & $\begin{array}{c}\text { Red } \\
105246\end{array}$ & 132 & 97 & - & NG & ok & - & oK & NG & - \\
\hline 17 & conts & 130 & 96 & - & oK & - & - & - & - & - \\
\hline x1 & Itod & 68 & 97 & 150 & NG & ok & - & NG & - & - \\
\hline 34 & Ioted & 119 & 99 & 25 & No & NO & ok & - & - & - \\
\hline
\end{tabular}

Fig. 15 Display of electronic triage server
- Tag ID, priority, vital sign, and physiological condition

- vital signs: pulse rate, $\mathrm{SpO}_{2}$, and breath rate

- physiological condition: walking, respiration, respiration after airway management, breath rate, pulse rate, and consciousness

The display of the electronic triage server is updated in real time. Therefore, this information enables a casualty to be found whose physiological conditions have drastically changed.

The electronic triage server can make the electronic triage tag to change to the notification mode when a casualty whose physiological condition drastically changes when the rescue commander finds such a casualty on the display.

Using the information on the server, the rescue commander can easily collect the overall physiological conditions of the casualties at the disaster scene, quickly find one whose physiological condition needs attention, and notify the rescue team. More lives can be saved by such quick responses of rescue commanders and rescue teams.

\subsection{Disaster rescue flow with electronic triage system}

This paper proposed a new electronic triage system that consists of two types of electronic triage tags, eTriage-full and eTriage-light, and an electronic triage server. This section introduces a new disaster medical operation flow using our electronic triage system.

1. Rescue: Rescue casualties from disaster points and transport them to the triage post.

2. Triage:

- Attachment: Place an electronic triage tag on casualties.

- Triage: Examine and input the physiological conditions of casualties to the electronic triage tags by pushing YES or NO buttons. The electronic triage tag decides a category for the casualties based on the input physiological conditions and turns on LEDs in the color that corresponds to the priority. During such severe situations mentioned in Sect. 4.2.2, the simple triage mode automatically triages casualties.

3. Measurement and monitoring: The electronic triage tag continuously measures a casualty's vital signs and wirelessly transmits them, its priority, and its physiological conditions to the server at the on-site rescue control center at the disaster scene in real time. Rescue commanders can easily collect the overall situation at disaster scenes in real time. 
4. Treatment and re-triage: If a casualty whose physiological condition drastically changes is found by monitoring on the server, the rescue commander sends a rescue team to it and for immediate treatment. After treatment, the casualty is re-triaged and its priority is updated.

5. Transport: Transport casualties to hospitals by ambulances, cars, or helicopters based the priority.

\section{Evaluation of electronic triage system}

This section introduces our experimental results that show the superiority of our proposed electronic triage system.

\subsection{Triage time}

The proposed electronic triage tag has a simple interface to input a casualty's physiological conditions. eTriage-light can be attached quickly and easily to a casualty just by inserting a finger into it. As mentioned in Sect. 3, we expect that casualties with severe physiological conditions will be attached to eTriage-full and that almost all others will be attached to eTriage-light. Therefore, in this experiment, we compared the triage times for the following two cases:

- Electronic triage tag (eTriage-light): A triage officer inputs the physiological conditions of a casualty by our proposed simple interface of the electronic triage tag, which automatically decides the casualty's priority based on the input, and shows the priority color by RGB LEDs.

- Paper triage tag: A triage officer writes down a casualty's physiological condition and its priority and removes the unused color tags.

In this experiment, a casualty has a symptom card on which age, gender, main complaint, vital signs (pulse rate, $\mathrm{SpO}_{2}$, and breath rate), and physiological conditions (walking, respiration, consciousness) are denoted. We measured the consumed time until a triage officer finished the triage from the time casualty opened a symptom.

In this experiment, one triage officer manages ten casualties, and we measured the required time five times (i.e., five different triage officers) for both cases. Table 3 shows the average triage time per casualty in both cases. The average triage time using the paper triage tags was

Table 3 Average triage time

\begin{tabular}{ll}
\hline Electronic triage tag & Paper triage tag \\
\hline $15.2(\mathrm{~s})$ & $28.5(\mathrm{~s})$ \\
\hline
\end{tabular}

$28.5 \mathrm{~s}$, and using the proposed electronic triage tag it was only $15.2 \mathrm{~s}$. This result shows that electronic triage tags can triage rapidly and are superior in terms of triage time.

\subsection{Life saving ratio}

Since our proposed electronic triage tags can measure vital signs and transmit them to the electronic triage server located at the on-site rescue control center, it can continuously monitor casualties and quickly respond to drastically changing physiological conditions. Therefore, we expect that our proposed triage system will save more lives than paper triage tags. This experiment compares the number of fatalities through a rescue simulation by the following three cases:

- using paper triage tag:

- using electronic triage tag:

- using electronic triage system (tag and server):

In this experiment, we assume ten casualties, all of whom are triaged, treated, and transported. Each casualty has a scenario, and the vital signs and casualty's condition change based on it. The following are defined in the scenarios used in our experiments:

- initial vital signs and physiological conditions

- new vital signs and physiological conditions after treatment

- required medical treatments for the physiological condition and time consumption for the treatments

- time when the casualty will die if he/she fails to receive suitable medical treatments

To neutralize any effect from the medical experience of the triage officers, we included required suitable medical treatments and treatment times for each physiological condition in the scenarios.

In these rescue simulation scenarios, eight of ten casualties could die. We assumed that time passes three times faster than in the real world and an ambulance arrives at the disaster scene every three minutes, i.e., nine minutes in the real world. In this rescue simulation, we defined success as when a casualty is still alive after being placed in an ambulance.

Table 4 shows the average number of fatalities in the seven triage simulations for the three cases (21 triage simulations in total). 2.23 casualties died using the paper

Table 4 Fatalities by paper triage tags, electronic triage tags, and electronic triage system

\begin{tabular}{lll}
\hline Paper triage tag & Electronic triage tag & Electronic triage system \\
\hline 2.23 & 1.7 & 1.4 \\
\hline
\end{tabular}


triage tags since the triage officer couldn't identify casualties whose conditions drastically changed without re-examining them. Since the triage officer might find a casualty in the same zone whose condition has drastically changed, 1.7 casualties died using the electronic triage tags. Since the triage officer might find a casualty in any zone whose condition has drastically changed in real time, only 1.4 casualties died with the electronic triage system. This result shows that our proposed electronic triage system can save more lives than the conventional triage method using paper triage tags.

Note that this experiment is just a pilot simulation. The number of casualties at the disaster scenes targeted by the proposed electronic triage system ranged from ten to hundreds (mainly tens). The number of casualties might be much fewer than our target disaster scene. To prepare a disaster situation with larger casualties is beyond the scope of this paper. Much progress of physiological conditions is required to make a large disaster scenario. However, sufficient progress at disaster scenes remains unrecorded. Therefore, preparing larger disaster scenarios is difficult.

We believe that this problem will be solved in the future when such electronic triage systems are practically used. Because they can record the progress of a casualty's physiological condition, we can accumulate much progress and establish accurate casualty models of disaster scenes. Since accurate models will enhance triage methods and the rescue flow, our proposed electronic triage system will save more lives.

\section{Conclusion}

This paper proposed an electronic triage system for disaster scenes that consists of two types of electronic triage tags and an electronic triage server. The electronic triage tags can be attached to a casualty and can continuously monitor its vital signs. Using the proposed triage system, a casualty whose physiological condition drastically changes can be found immediately for quick responses. Based on the experimental results, we conclude that the physiological condition of a casualty can be quickly inputted into electronic triage tags, and more lives can be saved using the proposed electronic triage system than paper triage tags.

Our proposed electronic triage system categorizes casualties. However, it does not determine the order of casualties for treatment and transportation. Rescue commanders decide treatment and transportation orders. Future work will enhance our electronic triage system so that it can decide the order of casualties or provide such information to rescue commanders.

Acknowledgments The authors are grateful to Prof. Hirozumi Yamaguchi, Prof. Akihito Hiromori, Prof. Akira Uchiyama, and Mr.
Junya Okamoto of Osaka University. This research was supported by JST, CREST.

Open Access This article is distributed under the terms of the Creative Commons Attribution License which permits any use, distribution, and reproduction in any medium, provided the original author(s) and the source are credited.

\section{References}

Ahn J, Heo J, Lim S, Seo J, Kim W (2008) A study of healthcare system for patient location data based on lbs. In: Proceedings of international conference on consumer electronics, pp 1-2

Banitsas KA, Istepanian RSH, Tachakra S, Owens TJ (2001) Modelling issues of wireless lans for accident and emergency departments. In: Proceeding of the 23rd annual EMBS international conference, vol 4, pp 3540-3543

Benson M, Koenig KL, Schultz CH (1996) Disaster triage: start, then save-a new method of dynamic triage for victims of a catastrophic earthquake. Prehosp Disaster Med 11(2):117-124

Cavouras D, Georgiadis P, Ninos K, Nomicos C (2008) Electromagnetic signals monitoring by smartphones and $3 \mathrm{~g}$ wireless networks. In: European Geosciences Union General Assembly 2008, p 2008

Fenza G, Furno D, Loia V (2012) Hybrid approach for context-aware service discovery in healthcare domain. J Comput Syst Sci 78(4):1232-1247

Gao T, Massey T, Selavo L, Crawford D, Chen B, Lorincz K, Shnayder V, Hauenstein L, Dabiri F, Jeng J, Chanmugam A, White D, Sarrafzadeh M, Welsh B (2007) The advanced health and disaster aid network: a light-weight wireless medical system for triage. IEEE Trans Biomed Circuits Syst 1(3):203-216

Gao T, Pesto C, Selavo L, Chen Y, Ko J, Lim J, Terzis A, Watt A, Jeng J, Chen B, Lorincz K, Welsh M (2008) Wireless medical sensor networks in emergency response: Implementation and pilot results. In: Proceedings of 2008 IEEE international conference on technologies for homeland security, pp 187-192

Georgiadis P, Banitsas K, Georgiou H, Sidiropoulos K, Tachakra S, Dimitropoulos N, Cavouras D (2004) A pda based teleradiology system. In: 1st international conference from scientific computing to computational engineering (1st IC-SCCE), p 89

Georgiadis P, Sidiropoulos K, Cavouras D, Banitsas K, Nomicos C (2006) Pda-based system for monitoring electromagnetic signal. In: Annual international conference on telecommunications and multimedia (TEMU 2006), pp 5-7

Kim Y, Le J (2008) A wearable health context aware system. In: International conference on consumer electronics (ICCE), pp $1-2$

Lorincz K, Malan DJ, Fulford-Jones TRF, Nawoj A, Clavel A, Shnayder V, Mainland G, Welsh M (2004) Sensor networks for emergency response: challenges and opportunities. IEEE Pervasive 3(4):16-23

Malan D, Fulford-Jones T, Welsh M, Moulton S (2004) Codeblue: an ad hoc sensor network infrastructure for emergency medical care. In: Proceedings of international workshop on wearable and implantable body sensor networks, pp 12-14

Maltz JS, Ng TSC, Li DJ, Wang J, Wang K, Bergeron W, Martin R, Budinger TF (2006) The trauma patient tracking system: implementing a wireless monitoring infrastructure for emergency response. In: 27th annual international conference of the Engineering in Medicine and Biology Society, pp 2441-2446

Midkiff SF, Bostian CW (2002) Rapidly-deployable broadband wireless networks for disaster and emergency response. In: 
Proceedings of the first IEEE workshop on disaster recover networks (DIREN '02), pp 1-10

Ninos K, Spiros K, Glotsos D, Georgiadis P, KSidiropoulos, Dimitropoulos N, Kalatzis I, Cavouras D (2010) Development and evaluation of a pda-based teleradiology terminal in thyroid nodule diagnosis. J Telemed Telecare 16(5):232-236

Pavlopoulos S, Kyriacou E, Berler A, Koutsouris SDD (1998) A novel emergency telemedicine system based on wireless communication technology-ambulance. IEEE Trans Inf Technol Biomed 2(4):261-267

Ryan T, Harrison M, Lipnicki V, Ramdial K (2011a) Technotriage digital triage system for low death/high casualty disaster scenarios. In: IEEE 37th annual northeast bioengineering conference (NEBEC) 2011, pp 1-2

Ryan T, Harrison M, Lipnicki V, Ramdial K (2011b) Technotriage digital triage system for low death/high casualty disaster scenarios. In: 2011 IEEE 37th annual northeast bioengineering conference (NEBEC), pp 1-2

Shnayder V, Chen B, Lorincz K, Jones TRFF, Welsh M (2005) Sensor networks for medical care. Harvard computer science technical reports for 205, TR-08-05

Sonoda A, Inoue S, Oka K, Fujisaki S (2007) Experiment of large scale triage with rfid tags. IPSJ J 48(2):802-810

Wendelken S, McGrath S, Blike G, Akay J (2004) The feasibility of using a forehead reflectance pulse oximeter for automated remote triage. In: Proceedings of the IEEE 30th annual northeast bioengineering conference 2004, pp 180-181

Yu X, Ganz A (2011) Scalable patients tracking framework for mass casualty incidents. In: Proceedings of international conference of the IEEE Engineering in Medicine and Biology Society (EMBC), pp 860-863 